\title{
A Study on the Evaluation of Field Application of High-Fluidity Concrete Containing High Volume Fly Ash
}

\author{
Yun-Wang Choi, Man-Seok Park, Byung-Keol Choi, and Sung-Rok Oh \\ Department of Civil Engineering, Semyung University, Jecheon 390-711, Republic of Korea \\ Correspondence should be addressed to Yun-Wang Choi; crete77@semyung.ac.kr
}

Received 1 May 2015; Revised 28 June 2015; Accepted 29 June 2015

Academic Editor: Ana S. Guimarães

Copyright (C) 2015 Yun-Wang Choi et al. This is an open access article distributed under the Creative Commons Attribution License, which permits unrestricted use, distribution, and reproduction in any medium, provided the original work is properly cited.

\begin{abstract}
In the recent concrete industry, high-fluidity concrete is being widely used for the pouring of dense reinforced concrete. Normally, in the case of high-fluidity concrete, it includes high binder contents, so it is necessary to replace part of the cement through admixtures such as fly ash to procure economic feasibility and durability. This study shows the mechanical properties and field applicability of high-fluidity concrete using mass of fly ash as alternative materials of cement. The high-fluidity concrete mixed with $50 \%$ fly ash was measured to manufacture concrete that applies low water/binder ratio to measure the mechanical characteristics as compressive strength and elastic modulus. Also, in order to evaluate the field applicability, high-fluidity concrete containing high volume fly ash was evaluated for fluidity, compressive strength, heat of hydration, and drying shrinkage of concrete.
\end{abstract}

\section{Introduction}

With concrete structures becoming larger, higher, and longer lately, the application of high-performance concrete with improved constructability, strength, and durability is required. Thus, various types of high-performance concrete are now being used in many countries around the world and have improved the performance of conventional concrete. In particular, the high-fluidity concrete, which fills forms only with the self-weight of concrete and with no compaction, is gaining recognition for its applicability to the placement of reinforced concrete structures with an overcrowded arrangement of bars due to the complex sections and seismic design of the structures.

On the other hand, with the rapid progress of global warming due to greenhouse gases (GHGs), many countries around the world are making diverse efforts to reduce their GHG emissions. To reduce GHG emissions in the concrete industry, various types of concrete are being developed and utilized using industrial byproducts as cement substitute materials. The recycling of such industrial byproducts is emerging as a sustainable construction technique because it preserves the environment and conserves energy, besides reducing GHG emissions. In this respect, interest is rising in the high volume fly ash concrete (HVFAC), which uses the fly ash (FA) generated after the combustion of pulverized coal in thermal power plants as an admixture for concrete. In other countries, since Malhotra developed HVFAC mixed with $50 \%$ or more FA in the 1980s, HVFAC has been used in various types of structures. In Europe, where the performance-centered design concept is used, the application scope of FA has been expanded by specifying the mixing ratio of 36-55\% for the FA in the CEM IV of EN 197.

The use of FA as an admixture for concrete has been reported to improve the performance of concrete by reducing its unit water content, increasing its fluidity and viscosity, controlling its drying shrinkage cracks, reducing its heat of hydration, and controlling its alkali-aggregate reaction. In the field, however, quality control for concrete is difficult using FA due to the quality variations of FA, inappropriate mixing ratios, and insufficient curing. High volume FA particularly has such problems as reduced early strength and delayed strength manifestation due to its low reactivity to $\mathrm{Ca}(\mathrm{OH})_{2}$ at the normal temperature. Thus, the early strength must be examined to allow the actual use of HVFA concrete. Basically, there are two methods of accelerating the pozzolan reaction of FA: physical and chemical methods. 
Payá et al. reported that the strength of mortar mixed with $15-60 \%$ physically pulverized fly ash increased in buildings aged three to 365 days [1]. However, Shi and Saraswathy et al. reported that the chemical method was more effective than the physical method $[2,3]$.

The pozzolan stimulants used in this chemical method are classified into sulfate activators and alkali activators.

For the sulfate activators, which accelerate the pozzolan reaction, $\mathrm{CaSO}_{4} \cdot 2 \mathrm{H}_{2} \mathrm{O}, \mathrm{CaSO}_{4}, \mathrm{Na}_{2} \mathrm{SO}_{4}$, and $\mathrm{K}_{2} \mathrm{SO}_{4}$ are used. $\mathrm{Xu}$ and Sarkar reported that the sulfate ions contributed to the improvement of early strength by destroying the vitreous, reacting with the aluminate components, and generating ettringite [4]. However, Poon and Ma et al. claimed that even though the sulfate activator improved the early strength, it did not contribute to the improvement of the strength of the long-term aged concrete $[5,6]$. Fraay et al. reported that the vitreous structure of fly ash was more brittle due to the alkalinity of the pore solution and the high-alkaline water solution, which activated the pozzolan reaction [7]. For the alkali activators to accelerate the pozzolan reaction of fly ash, high-density $\mathrm{Ca}(\mathrm{OH})_{2}, \mathrm{NaOH}, \mathrm{KOH}$, and water glass are used.

However, these methods are difficult to apply in the field due to their low fluidity and the high concrete unit prices when the high-fluidity HVFA concrete is produced.

Therefore, in this study, to achieve early strength at the normal temperature, a high-fluidity HVFA concrete with a $50 \%$ fly ash mixing ratio and a changed unit water content and binder content was produced, and its mechanical characteristics and field applicability were evaluated.

\section{Experimental Work}

\subsection{Materials Used and Mix Proportions}

2.1.1. Cement and Admixture. For the cement, ordinary Portland cement (hereinafter referred to as "OPC") with a density of $3.15 \mathrm{~g} / \mathrm{cm}^{3}$ and a fineness of $3,540 \mathrm{~cm}^{2} / \mathrm{g}$ was used. For the admixture, fly ash (hereinafter referred to as "FA") with a density of $2.20 \mathrm{~g} / \mathrm{cm}^{3}$ and a fineness of $3,480 \mathrm{~cm}^{2} / \mathrm{g}$ was used. Table 1 shows the chemical compositions and physical properties of the cement and the FA.

2.1.2. Aggregates and Chemical Admixtures. For the fine aggregates, river sand (hereinafter referred to as " $\mathrm{S}$ ") from the Nakdong River was used; and for the coarse aggregates, granitic crushed aggregates (hereinafter referred to as " $G$ ") with a maximum size $\left(G_{\max }\right)$ of $20 \mathrm{~mm}$ were used. The physical properties of $S$ and $G$ are shown in Table 2. For the chemical admixtures for the fluidity and air content control of the high-fluidity HVFA concrete, a polycarboxylic superplasticizer (hereinafter referred to as "SP") and an air-entraining agent (hereinafter referred to as "AE") were used.

\subsection{Experiment Method}

2.2.1. Concrete Mix. To evaluate the mechanical characteristics of the high-fluidity HVFA concrete, a 50\% FA mixing
TABLE 1: Chemical compositions and physical properties of cement and FA.

\begin{tabular}{lcc}
\hline Type & Cement & FA \\
\hline $\mathrm{CaO}(\%)$ & 61.60 & 6.49 \\
$\mathrm{SiO}_{2}(\%)$ & 19.80 & 48.30 \\
$\mathrm{Al}_{2} \mathrm{O}_{3}(\%)$ & 4.50 & 25.50 \\
$\mathrm{MgO}(\%)$ & 3.01 & 1.67 \\
$\mathrm{Fe}_{2} \mathrm{O}_{3}(\%)$ & 3.57 & 8.50 \\
$\mathrm{SO}_{3}(\%)$ & 2.10 & 0.40 \\
$\mathrm{~L} . \mathrm{O} . \mathrm{I}(\%)$ & 1.20 & 3.80 \\
Surface area $\left(\mathrm{cm}^{2} / \mathrm{g}\right)$ & 3,450 & 3,480 \\
Density $\left(\mathrm{g} / \mathrm{cm}^{3}\right)$ & 3.15 & 2.20 \\
\hline
\end{tabular}

TABLE 2: Physical properties of aggregates.

\begin{tabular}{lccccc}
\hline Type & $\begin{array}{c}G_{\max } \\
(\mathrm{mm})\end{array}$ & $\begin{array}{c}\text { Density } \\
\left(\mathrm{g} / \mathrm{cm}^{3}\right)\end{array}$ & $\begin{array}{c}\text { Absorption } \\
(\%)\end{array}$ & F.M. & $\begin{array}{c}\text { Bulk } \\
\text { density } \\
\left(\mathrm{kg} / \mathrm{m}^{3}\right)\end{array}$ \\
\hline $\mathrm{S}$ & - & 2.58 & 1.37 & 2.57 & 1,603 \\
$\mathrm{G}$ & 20 & 2.68 & 0.77 & 6.78 & 1,601 \\
\hline
\end{tabular}

TABLE 3: The proportion of high volume fly ash HFC.

\begin{tabular}{lccccccc}
\hline \multicolumn{2}{l}{ Type } & W/B & \multicolumn{5}{c}{ Unit mass $\left(\mathrm{kg} / \mathrm{m}^{3}\right)$} \\
& & $(\%)$ & W & OPC & FA & S & G \\
\hline A & OPC & 35 & 167 & 480 & 0 & 806 & 900 \\
B & FA 50 & 35 & 167 & 240 & 240 & 763 & 852 \\
C & W 110 & 23 & 110 & 240 & 240 & 834 & 931 \\
D & W 120 & 25 & 120 & 240 & 240 & 822 & 916 \\
E & W 130 & 27 & 130 & 240 & 240 & 809 & 904 \\
F & W 140 & 29 & 140 & 240 & 240 & 797 & 890 \\
G & W 150 & 31 & 150 & 240 & 240 & 784 & 876 \\
H & B 522 & 23 & 120 & 261 & 261 & 802 & 896 \\
I & B 480 & 25 & 120 & 240 & 240 & 822 & 918 \\
J & B 446 & 27 & 120 & 223 & 223 & 836 & 936 \\
K & B 414 & 29 & 120 & 207 & 207 & 853 & 953 \\
L & B 388 & 31 & 120 & 194 & 194 & 866 & 967 \\
\hline
\end{tabular}

ratio, based on the OPC proportioning strength of $50 \mathrm{MPa}$, was used as the plain condition. To improve the mechanical characteristics of the 50\% FA mixing ratio, concrete mixing was performed for five levels of the unit water content and five levels of the binder content. Furthermore, concrete mixing was performed to satisfy the slump flow of $650 \pm 50 \mathrm{~mm}$ and the air content of $3.5 \pm 1.5 \%$. The concrete mix experimented on is shown in Table 3.

2.2.2. The Fluidity. To evaluate the fluidity of the high-fluidity HVFA concrete, the slump flow was measured with ASTM C 1611, and the air content was tested with STM C 231.

2.2.3. The Mechanical Properties. The compressive strength test of concrete was performed in accordance with ASTM 


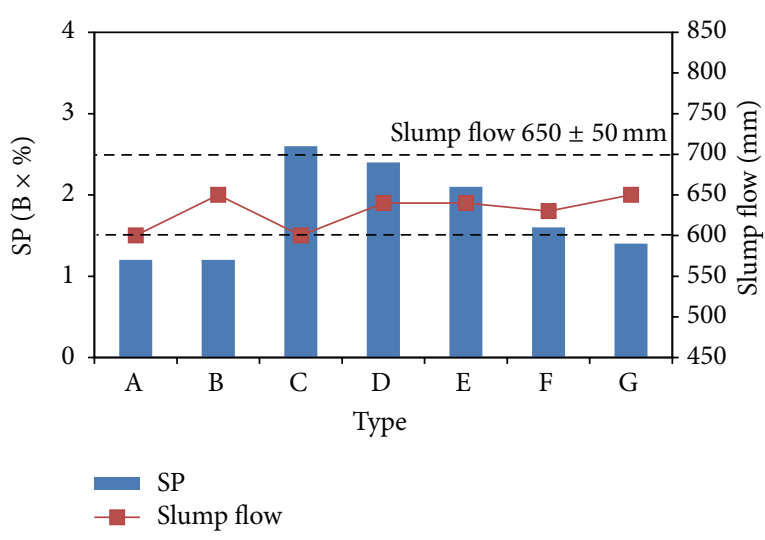

(a) The change of the water content

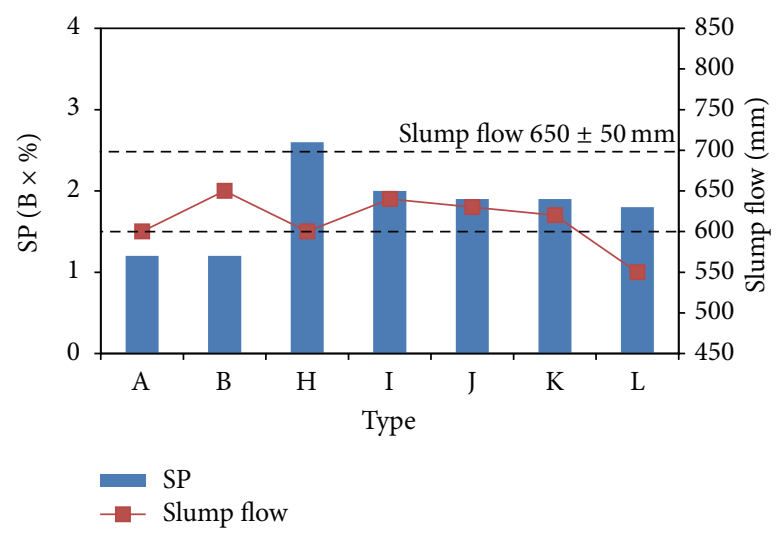

(b) The change of the binder content

FIGURE 1: The fluidity of high volume fly ash HFC with superplasticiser content.

TABLE 4: Mixing proportion of concrete in site.

\begin{tabular}{ccccccc}
\hline \multirow{2}{*}{ Type } & W/B & \multicolumn{5}{c}{ Unit mass $\left(\mathrm{kg} / \mathrm{m}^{3}\right)$} \\
& $(\%)$ & W & OPC & FA & S & G \\
\hline Plain & & & & & & \\
OPC & 35 & 167 & 480 & 0 & 806 & 900 \\
FA 50\% & & & & & & \\
W 110 & 25 & 110 & 216 & 216 & 857 & 957 \\
W 120 & 25 & 120 & 240 & 240 & 822 & 918 \\
W 130 & 25 & 130 & 257 & 257 & 793 & 886 \\
\hline
\end{tabular}

C 39, and the test specimen was produced with a $\varnothing 100 \times$ $200 \mathrm{~mm}$ cylindrical mold with no compaction. The specimen was cured through standard curing in a curing water tank at $20 \pm 2^{\circ} \mathrm{C}$ until it was 28 days old, the compressive strength was measured at each age, and the static modulus of elasticity was measured at 28 days of age.

2.2.4. Field Mock-Up Test. To evaluate the field applicability of the high-fluidity HVFA concrete, concrete was produced with an on-site ready-mix truck based on the plain mix with a design strength of $50 \mathrm{MPa}$ and a $25 \% \mathrm{~W} / \mathrm{B}$ ratio at the unit quantities of 110,120 , and $130 \mathrm{~kg} / \mathrm{m}^{3}$. Then experiments were conducted on the compressive strength, adiabatic temperature rise, and length change. The field mock-up concrete mix is shown in Table 4.

\section{Results and Discussion}

\subsection{Fluidity}

3.1.1. Slump Flow. Figures 1(a) and 1(b) show the used quantities of SP according to the changing unit water content and binder content to satisfy the $650 \pm 50 \mathrm{~mm}$ target slump at the 50\% FA mixing ratio. As shown in Figure 1(a), the used quantity of SP tended to decrease as the unit water content increased; and as shown in Figure 1(b), the used quantity of SP tended to decrease as the binder content decreased. Furthermore, the used quantity of SP ranged from 1.2 to 2.2 times the used quantity of the OPC high-fluidity concrete as the unit water content decreased and from 1.6 to 2.2 times as the binder content increased. It seems that grain shape and packing effect increased the fluidity of fly ash, but the decrease in the unit water content reduced the fluidity and increased the use of high-performance water reducing agent. The L mix did not satisfy the $650 \pm 50 \mathrm{~mm}$ target slump criterion. This was seemingly because viscosity was not achieved due to the lack of the binder content needed to achieve the required viscosity in the production of high-fluidity concrete. The minimum binder content needed to produce high-fluidity HVFA concrete is about $400 \mathrm{~kg} / \mathrm{m}^{3}$.

3.1.2. Air Content. Figures 2(a) and 2(b) show the used quantities of $\mathrm{AE}$ according to the changing unit water content and binder content to satisfy the $3.5 \pm 1.5 \%$ target air content at the $50 \%$ FA mixing ratio. As shown in Figures 2(a) and 2(b), the air content tended to increase as the unit water content increased and as the binder content decreased. Furthermore, the $\mathrm{AE}$ range needed to satisfy the target air content was about twice that of the OPC high-fluidity concrete. This was seemingly due to the air adsorption of the combustible carbon in FA.

\subsection{Mechanical Characteristics}

3.2.1. Compressive Strength. Figures 3(a) and 3(b) show the compressive strength according to the changing unit water content (at the $480 \mathrm{~kg} / \mathrm{m}^{3}$ fixed binder content) and the changing binder content (at the $120 \mathrm{~kg} / \mathrm{m}^{3}$ fixed unit water content) at the 50\% FA mixing ratio. As shown in Figure 3(a), the strength at 1 day of Mix B with a 50\% FA mixing ratio decreased by about $86 \%$ compared to Mix A. Furthermore, for Mixes C, D, E, F, and G, in which the unit water content was varied at a fixed binder content, the strength at 1 day increased as the unit water content decreased. The strength at 1 day of Mix C increased by about 3.2 times that of Mix B. 


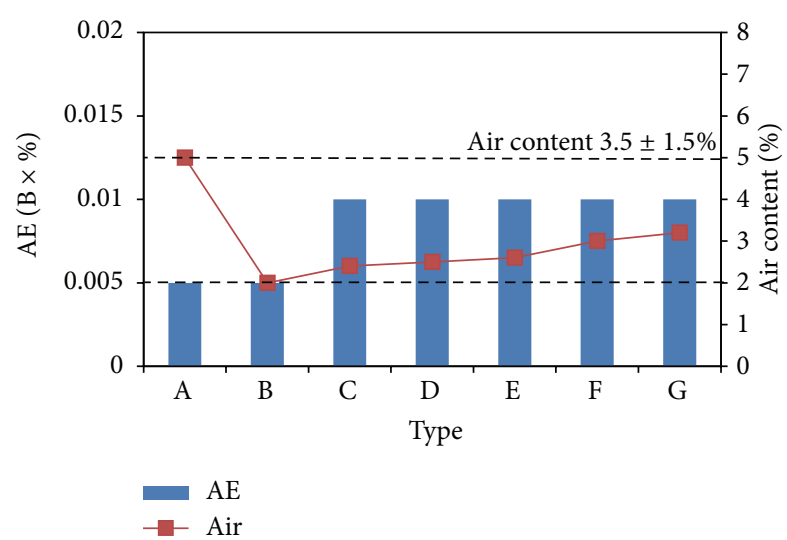

(a) The change of the water content

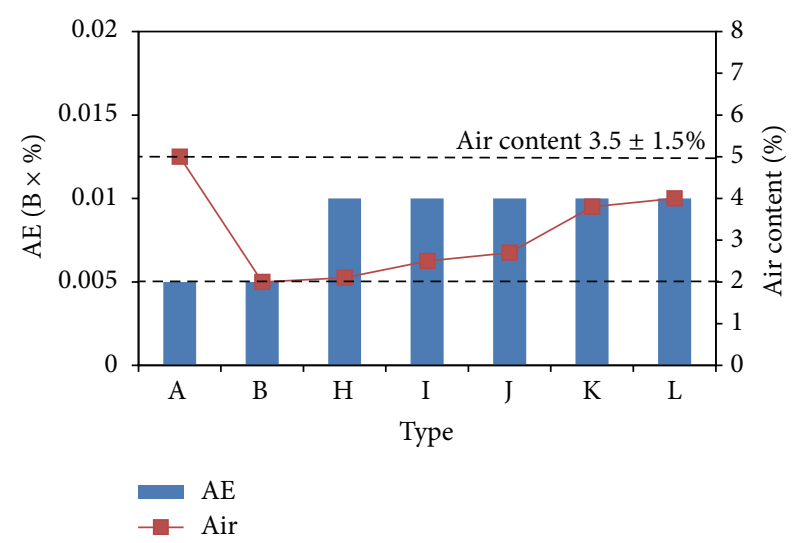

(b) The change of the binder content

FIGURE 2: The air content of high volume fly ash HFC with air-entraining agent content.

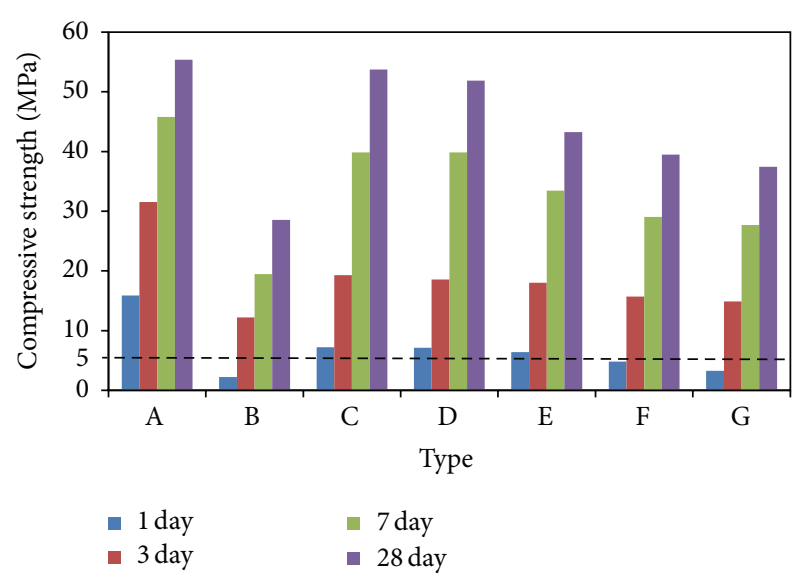

(a) The change of the water content

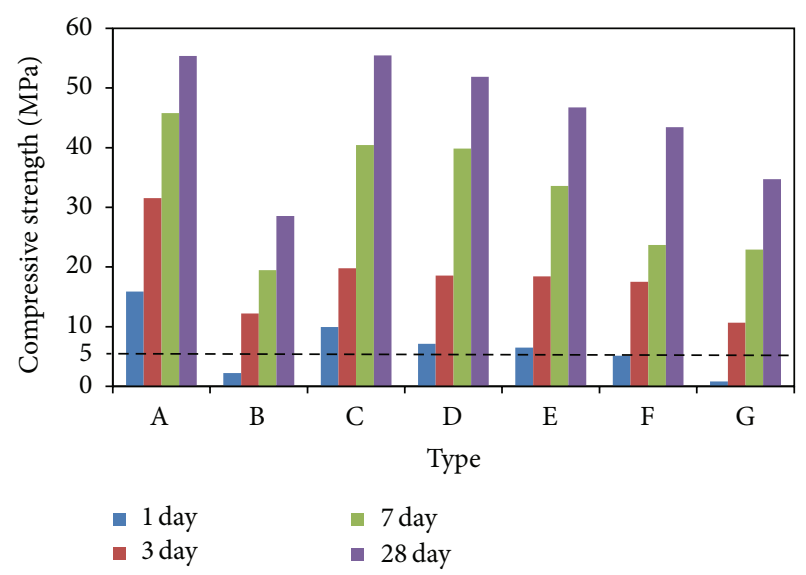

(b) The change of the binder content

FIGURE 3: The compressive strength of high volume fly ash HFC.

When the form removal time was considered, Mixes $\mathrm{C}$, $\mathrm{D}$, and $\mathrm{E}$ satisfied the form removal strength of $5 \mathrm{MPa}$ at 1 day. When $50 \%$ of the FA was mixed, the unit water content of about $130 \mathrm{~kg} / \mathrm{m}^{3}$ was expected to decrease to achieve the compressive strength at the early age. At the age of 28 days, the compressive strength increased as the unit water content decreased.

As shown in Figure 3(b), for Mixes H, I, J, K, and L, in which the binder content was varied at a fixed unit water content, the strength at 1 day increased as the binder content increased. At day 1, the strength of Mix $\mathrm{H}$ increased by about 4.5 times compared to that of Mix B. In the case of the mixture according to the unit water content, the remaining free water that was not consumed by hydration in the concrete because of the decrease in the unit water content with the same amount of binder content seemingly increased the compressive strength. In the case of the mixture according to the binder content, the increase in the binder content with the same unit water content seemingly increased the hydration products, and the packing effect of FA made the inside denser, thus increasing the compressive strength.
When the form removal time was considered, Mixes $\mathrm{H}$, $\mathrm{I}$, J, and $\mathrm{K}$ satisfied the form removal strength of $5 \mathrm{MPa}$ at 1 day. When $50 \%$ of the FA was mixed, a binder content of at least $400 \mathrm{~kg} / \mathrm{m}^{3}$ was expected to be required to achieve the compressive strength at the early age [8].

In addition, the compressive strength of the high-fluidity HVFA concrete increased with age, seemingly because the inside became denser due to the pozzolan reaction (as shown in the comparison between 3 days and 28 days in Figure 4). On the 28th day, however, the pozzolan reaction products did not completely fill the pores around the FA, and there were pores that were not close to the matrix, as shown in the magnified picture of the FA.

3.2.2. Modulus of Elasticity. Figures 5(a) and 5(b) show the relationships between the compressive strength and the static modulus of elasticity of the high-fluidity HVFA concrete according to the changing unit water content and binder content. As shown in Figures 5(a) and 5(b), the results were similar to the prediction values at all levels according to 


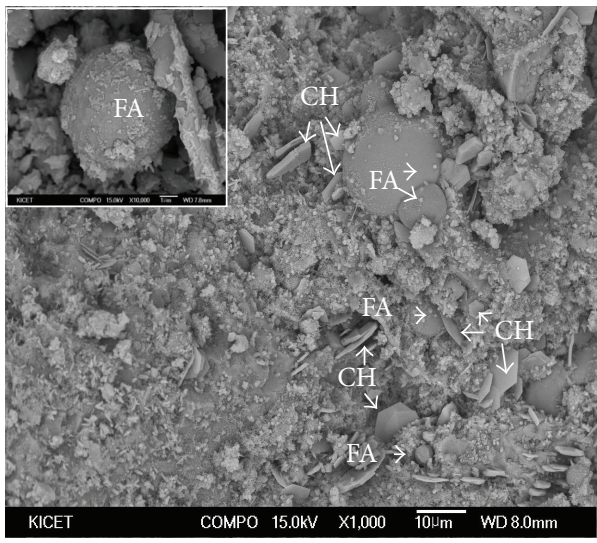

(a) 3 days $(\times 1000)$

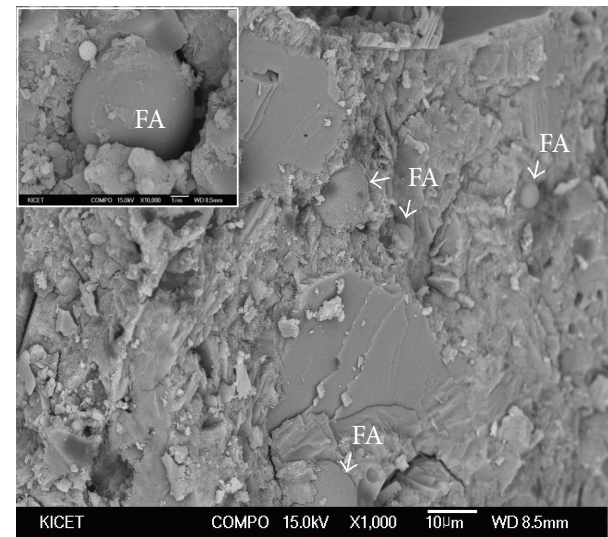

(b) 28 days $(\times 1000)$

FIGURE 4: The SEM of high volume fly ash HFC.

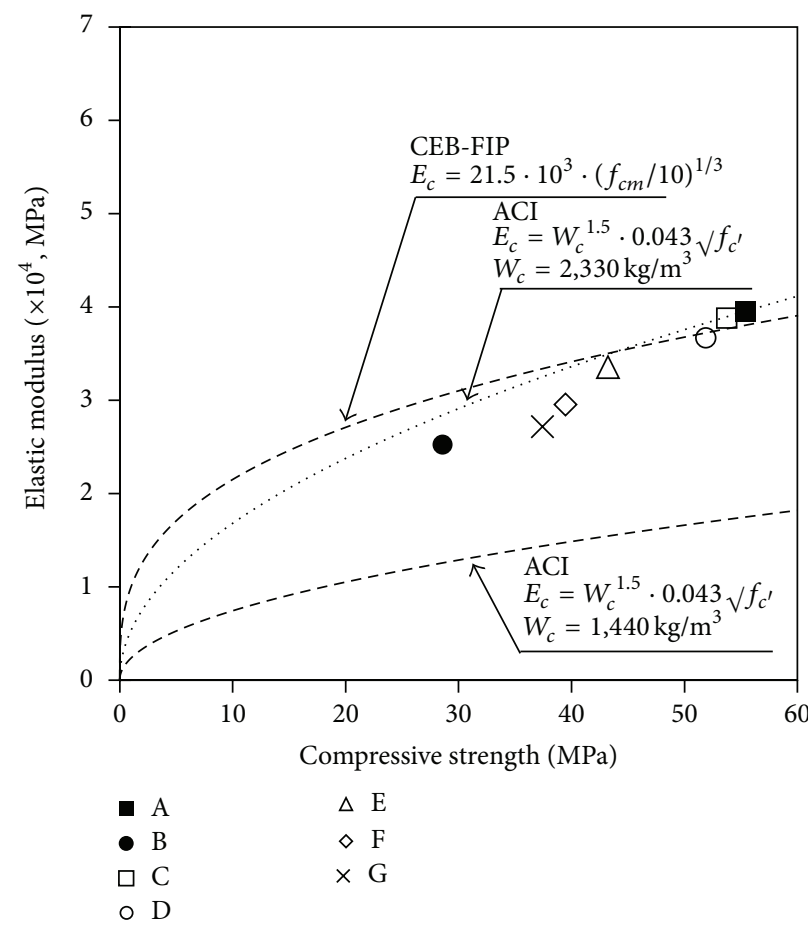

(a) The change of the water content

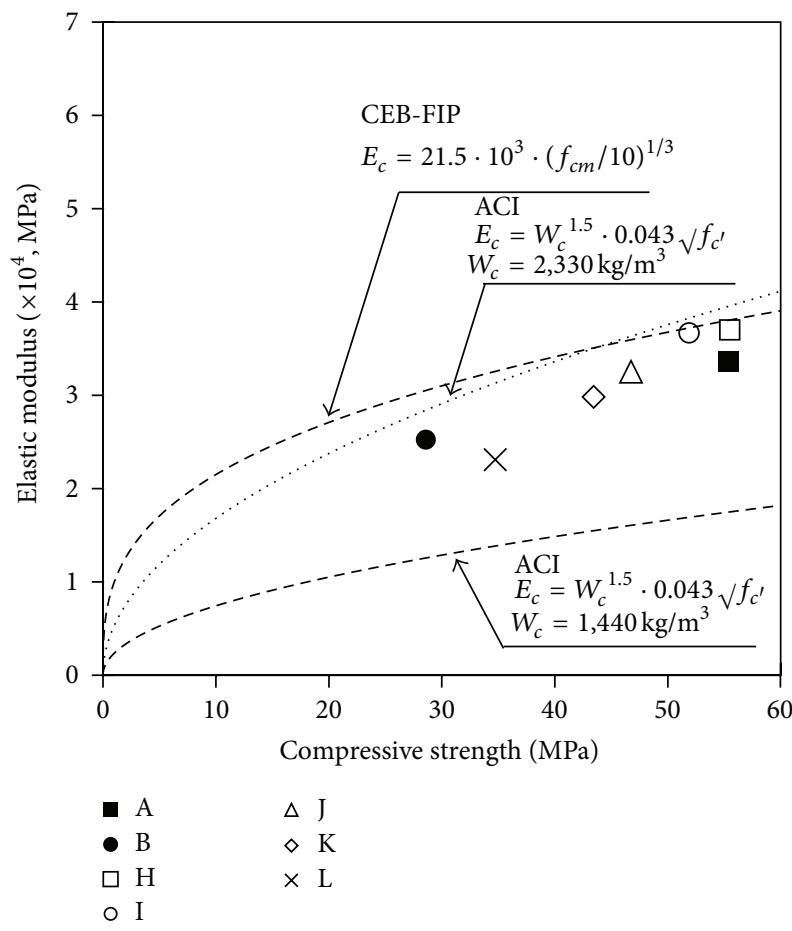

(b) The change of the binder content

FIgURE 5: The relationship with the compressive strength and coefficient of elasticity of high volume fly ash HFC.

the concrete elasticity prediction formulas presented in CEBFIP CODE and ACI 318. These results indicate that the relationship between the compressive strength and the static modulus of elasticity of the high-fluidity HVFA concrete can stabilize its elasticity, as with conventional concrete.

\subsection{Field Application Characteristics}

3.3.1. Fluidity. The field fluidity of the high-fluidity HVFA concrete achieved both the $650 \pm 50 \mathrm{~mm}$ target slump and the $3.5 \pm 1.5 \%$ target air content.
3.3.2. Compressive Strength. Figure 6 shows the results of the measurement of the compressive strength of the high-fluidity HVFA concrete when the unit water content was varied to three levels $\left(130,120\right.$, and $\left.110 \mathrm{~kg} / \mathrm{m}^{3}\right)$ at the water-binder ratio of $25 \%$ for the plain high-fluidity concrete. As shown in Figure 6, the compressive strength tended to decrease as the unit water content and the binder content decreased. At the unit water content of $130 \mathrm{~kg} / \mathrm{m}^{3}$, the strength at 7 days was about $45 \%$ lower than that of the plain high-fluidity concrete, but the strength at 28 days satisfied the target strength. 


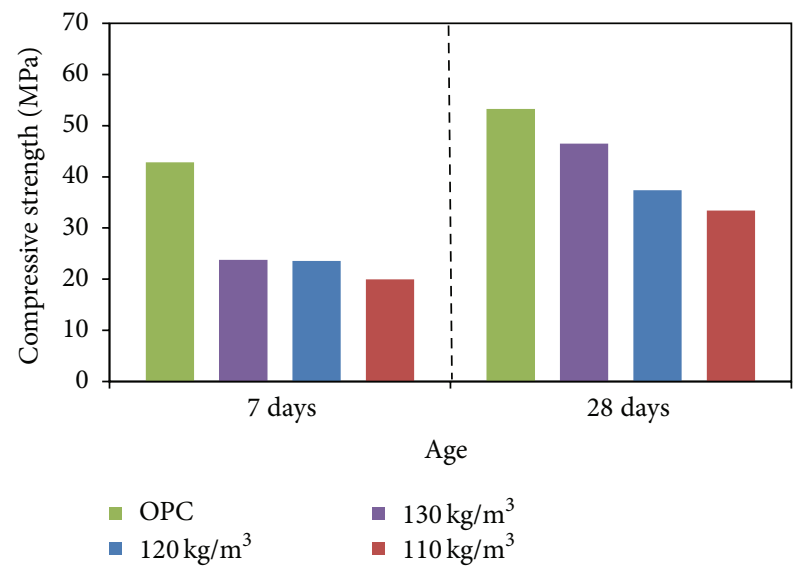

FIGURE 6: The compressive strength of high volume fly ash HFC in field.

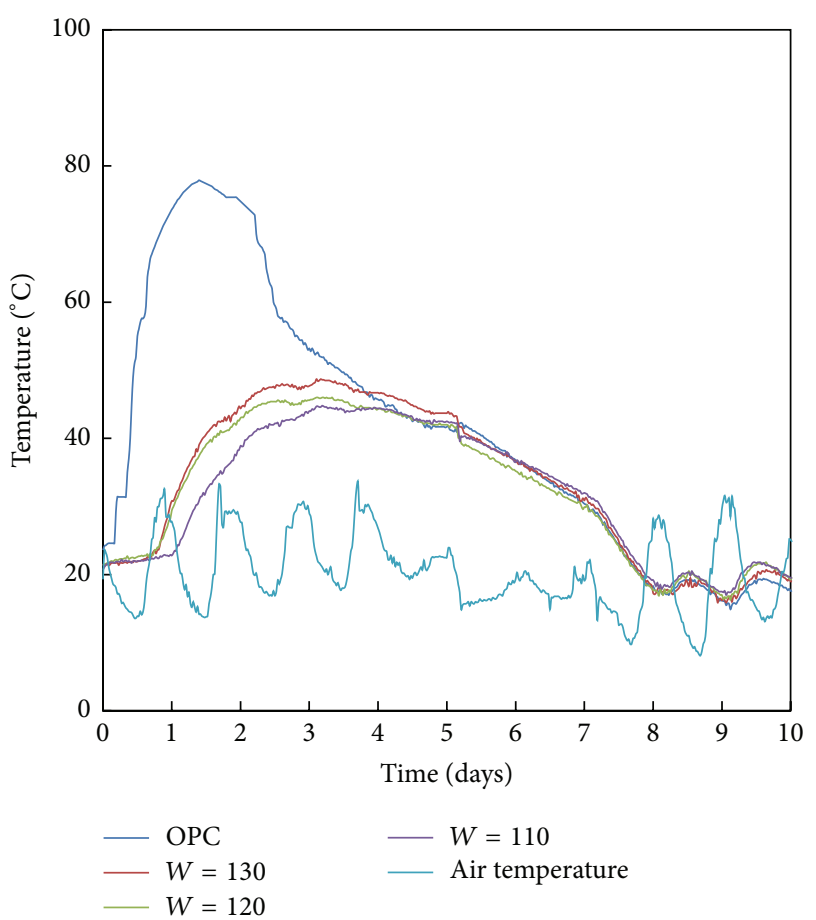

FIGURE 7: The heat of hydration of high volume fly ash HFC in field.

3.3.3. Heat of Hydration. Figure 7 shows the rising curve of the field heat of hydration of the high-fluidity HVFA concrete when the unit water content was varied to three levels (130, 120 , and $110 \mathrm{~kg} / \mathrm{m}^{3}$ ) at the water-binder ratio of $25 \%$ for the plain high-fluidity concrete. As shown in Figure 6, the heat of hydration of the plain high-fluidity concrete rose to about $80^{\circ} \mathrm{C}$ and that of the high-fluidity HVFA concrete rose to about $48^{\circ} \mathrm{C}$. The increase in the heat of hydration decreased as the binder content decreased. These results indicate that when at least $50 \%$ FA is mixed, an approximately $40 \%$ or higher reduction effect of the heat of hydration can be achieved due to the decrease in the heat of hydration at the early age.

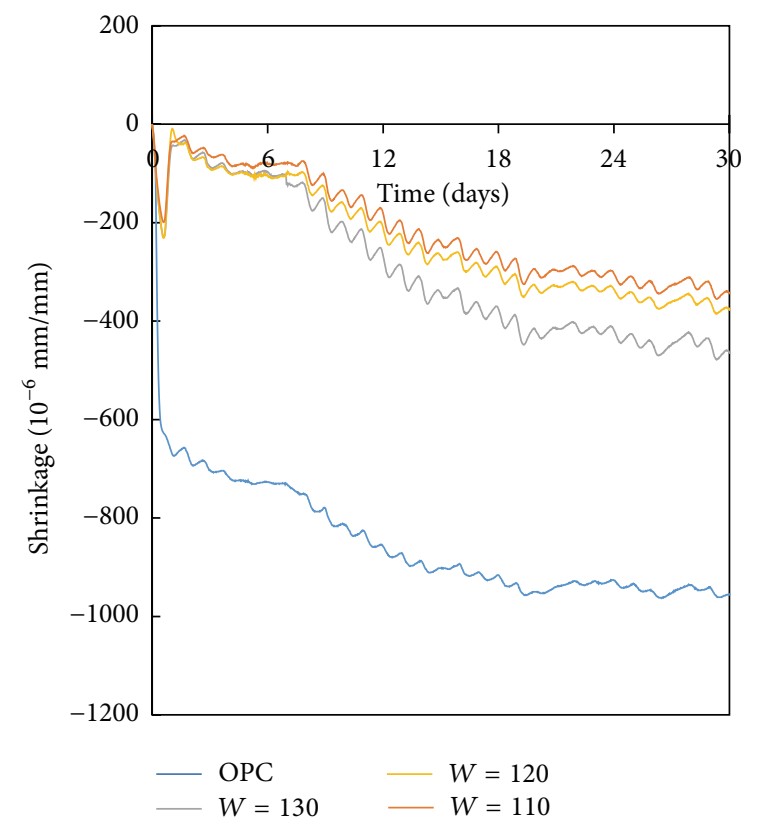

FIGURE 8: The drying shrinkage of high volume fly ash HFC in field.

3.3.4. Drying Shrinkage. Figure 8 shows the drying shrinkage of the high-fluidity HVFA concrete when the unit water content was varied to three levels $\left(130,120\right.$, and $\left.110 \mathrm{~kg} / \mathrm{m}^{3}\right)$ at the water-binder ratio of $25 \%$ for the plain high-fluidity concrete. As shown in Figure 8, the drying shrinkage of the plain high-fluidity concrete was about $972 \times 10^{-6} \mathrm{~mm}$ at 30 days, and the maximum drying shrinkage of the high-fluidity HVFA concrete was about $482 \times 10^{-6} \mathrm{~mm}$. Furthermore, the shrinkage tended to decrease as the binder content decreased. These results indicate that when at least $50 \% \mathrm{FA}$ is mixed, an approximately $50 \%$ or higher reduction effect of the drying shrinkage can be achieved.

\section{Conclusions}

This study was a basic research on the field application of the high-fluidity HVFA concrete that contains $50 \%$ FA. The following results were obtained.

(1) Large quantities of the superplasticizer and the airentraining agent will be required to satisfy the required fluidity as the unit water content decreases and the binder content increases to attain the early strength of the high-fluidity HVFA concrete.

(2) The early strength of the high-fluidity HVFA concrete increased as the unit water content decreased and the binder content increased. For the compressive strength, the rate of the strength development seemed to have increased due to the pozzolan reaction through the mixing of large quantities of FA according to the age.

(3) When $50 \%$ FA is mixed, the unit water content of $130 \mathrm{~kg} / \mathrm{m}^{3}$ or less and the binder content of $400 \mathrm{~kg} / \mathrm{m}^{3}$ 
or higher will be required to achieve the early strength.

(4) For the field applicability of high-fluidity HVFA concrete, the compressive strength can achieve a performance similar to that of the general case, through the adjustment of the unit water content and the binder content. The hydration rise and the drying shrinkage improved compared to the general OPC. Therefore, the high-fluidity HVFA concrete would effectively reduce the heat of hydration and shrinkage when applied in the field.

\section{Conflict of Interests}

The authors declare that there is no conflict of interests regarding the publication of this paper.

\section{Acknowledgment}

This work was supported by the research fund of Korea institute of Energy Technology Evaluation and Planning (KETEP) (20111010100030).

\section{References}

[1] J. Payá, J. Monzó, M. V. Borrachero, E. Peris, and E. GonzálezLópez, "Mechanical treatments of fly ashes. Part III: studies on strength development of ground fly ashes (GFA) - cement mortars," Cement and Concrete Research, vol. 27, no. 9, pp. 13651377, 1997.

[2] C. Shi, Activation of natural pozzolans, fly ashes and blast furnace slag [Dissertation], The University of Calgary, Calgary, Canada, 1992.

[3] V. Saraswathy, S. Muralidharan, K. Thangavel, and S. Srinivasan, "Influence of activated fly ash on corrosion-resistance and strength of concrete," Cement and Concrete Composites, vol. 25, no. 7, pp. 673-680, 2003.

[4] A. Xu and S. L. Sarkar, "Microstructural study of gypsum activated fly ash hydration in cement paste," Cement and Concrete Research, vol. 21, no. 6, pp. 1137-1147, 1991.

[5] C. S. Poon, S. C. Kou, L. Lam, and Z. S. Lin, "Activation of fly ash/cement systems using calcium sulfate anhydrite $\left(\mathrm{CaSO}_{4}\right)$," Cement and Concrete Research, vol. 31, no. 6, pp. 873-881, 2001.

[6] W. Ma, C. Liu, P. W. Brown, and S. Komarneni, "Pore structures of fly ashes activated by $\mathrm{Ca}(\mathrm{OH})_{2}$ and $\mathrm{CaSO}_{4} \cdot 2 \mathrm{H}_{2} \mathrm{O}$," Cement and Concrete Research, vol. 25, no. 2, pp. 417-425, 1995.

[7] A. L. A. Fraay, J. M. Bijen, and Y. M. de Haan, "The reaction of fly ash in concrete. A critical examination," Cement and Concrete Research, vol. 19, no. 2, pp. 235-246, 1989.

[8] Y. W. Choi, M. S. Park, B. K. Choi, and S. R. Oh, “The properties of strength development of high volume fly ash concrete with reduction of unit water content," Journal of the Korean Recycled Construction Resources Institute, vol. 2, no. 1, pp. 46-51, 2014. 

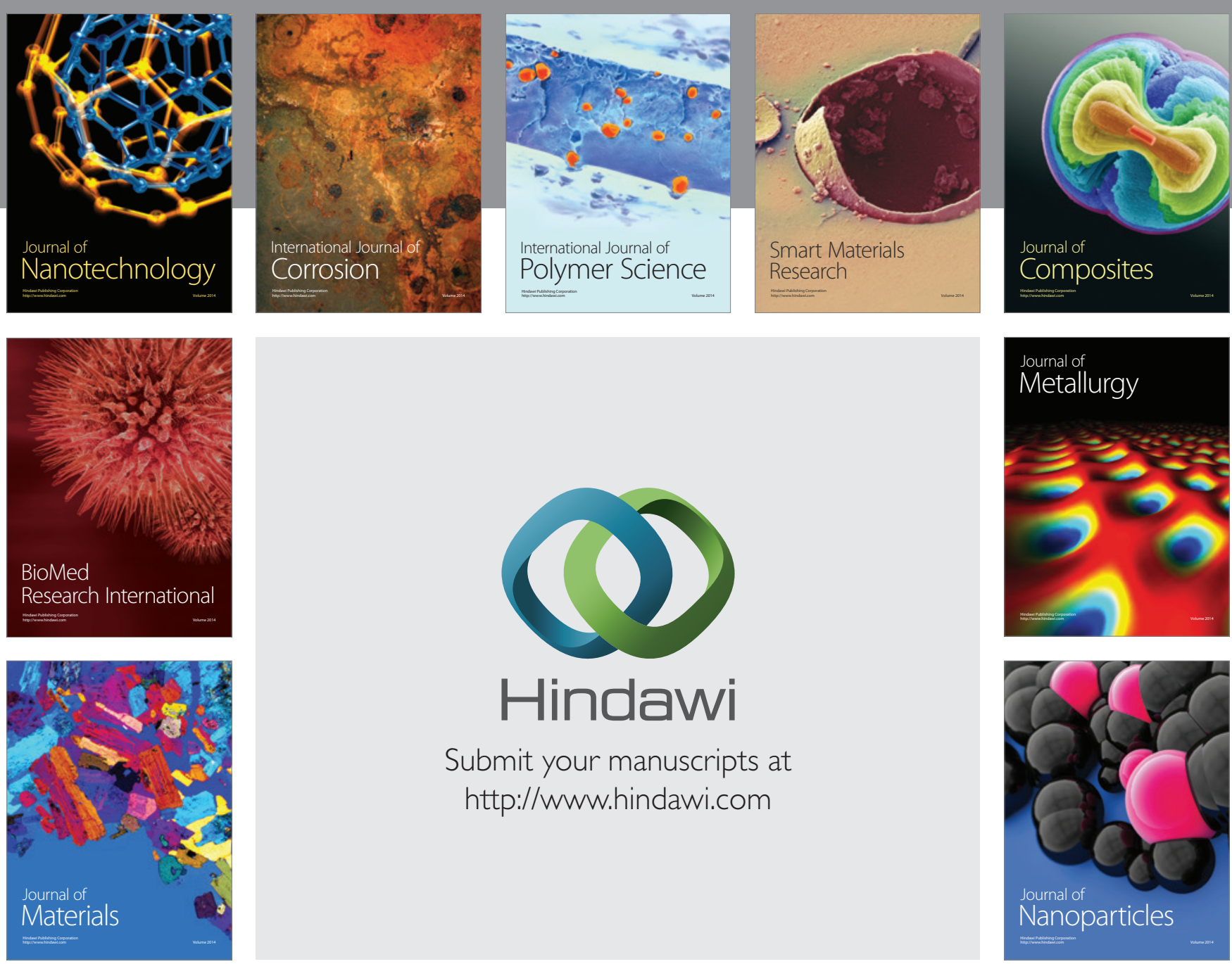

Submit your manuscripts at http://www.hindawi.com
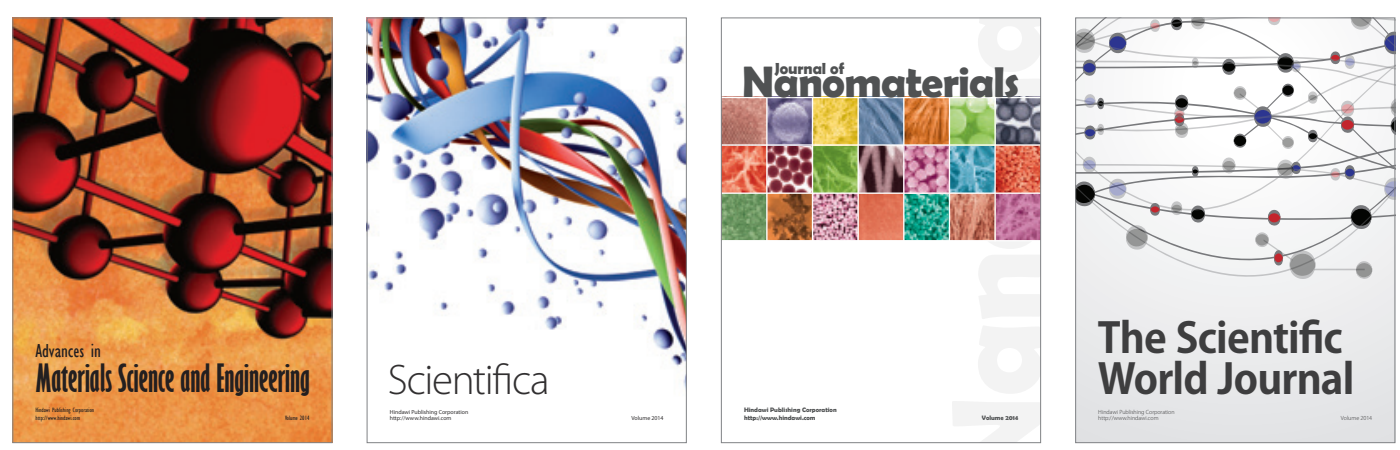

\section{The Scientific World Journal}
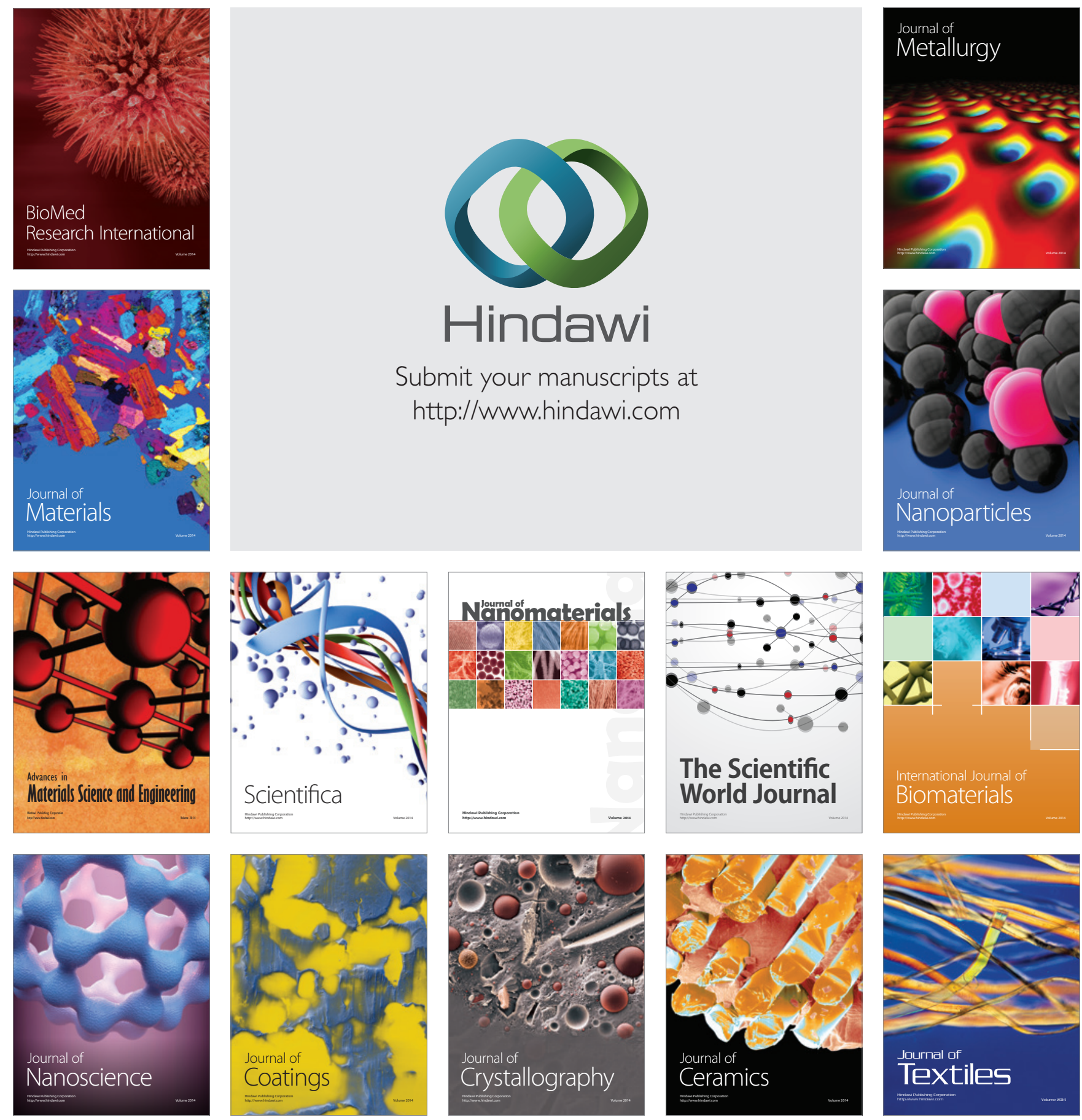